\title{
Recommendations for cervical cancer screening programs in developing countries. The need for equity and technological development
}

\author{
Eduardo Lazcano-Ponce, MD, Dr Sc., (1) PatriciaAlonso, MD., (2) \\ José Antonio Ruiz-Moreno, MD., ${ }^{(3)}$ Mauricio Hernández-Avila MD, Dr Sc. ${ }^{(1)}$
}

\begin{abstract}
Lazcano-Ponce E,Alonso $P$,
Ruiz-Moreno JA, Hernández-Avila M.

Recommendations for cervical cancer screening programs in developing countries. The need for equity and technological development. Salud Publica Mex 2003;45 suppl 3:S449-S462. This paper is available too at: http://www.insp.mx/salud/index.html
\end{abstract}

\begin{abstract}
A bstract
The cervical cancer screening programs (CCSP) have not been very efficient in the developing countries.T his explains the need to foster changes on policies, standards, quality control mechanisms, evaluation and integration of new screening alternatives considered as low and high cost, as well as to regulate colposcopy practices and the foundation of HPV laboratories. Cervical cancer (CC) is a disease most frequently found in poverty-stricken communities and reflecting a problem of equity at both levels gender and regional, and this, is not only due to social and economic development inequalities, but to the infrastructure and human resources necessary for primary care. For this reason, the CCSP program must be restructured, a) to primarily address unprivileged rural and urban areas; $b$ ) to foster actions aimed at ensuring extensive coverage as well as a similar quality of that coverage in every region; c) to use screening strategies in keeping with the availability of health care services. In countries with a great regional heterogeneity, a variety of screening procedures must be regulated and standardized, including a combination of assisted visual inspection, cervical cytology and HPV detection; d) regional community inter vention must be set up to assess the effectiveness of using HPV detection as an strategy in addition to cervical cytology
\end{abstract}

\author{
Lazcano-Ponce E,Alonso $P$, \\ Ruiz-Moreno JA, Hernández-Avila M. \\ Recomendaciones a programas de detección oportuna \\ de cáncer cervical en países en desarrollo. Necesidad \\ de equidad y desarrollo tecnológico. \\ Salud Publica Mex 2003;45 supl 3:S449-S462. \\ Este artículo también está disponible en: \\ http://www.insp.mx/salud/index.html
}

\section{Resumen}

Los programas poblacionales de detección oportuna de cáncer cervical (D O C) han sido poco eficientes en países en desarrollo. Por esta razón, es necesario impulsar cambios en las políticas, normatividad, mecanismos de control de calidad, evaluación e integración de nuevas alternativas de tamizaje consideradas de bajo y alto costo, así como la regulación de la práctica de colposcopía y de la futura integración de laboratorios para el VPH. El cáncer cervicouterino (CC) es una enfermedad de la pobreza que refleja un problema de equidad de género y de equidad regional, no sólo en cuanto a diferencias de desarrollo económico y social, sino en cuanto a la infraestructura física y de recursos humanos que otorgan servicios de atención primaria. Por esta razón, un programa de DOC debe reorganizarse para: a) dirigirse predominantemente a regiones geo gráficas rurales y urbanas marginadas, b) impulsar acciones que garanticen una cobertura ampliada y calidad similar en todas las regiones, c) utilizar estrategias de tamizaje acordes con la disponibilidad de servicios de atención médica. En países con gran heterogeneidad regional deben regularse y normar se diversos escenarios de tamizaje que incluyan la combinación de imagen visual asistida, citología cervical y determinación del VPH, d) se deben iniciar

(1) Centro de Investigación en Salud Poblacional. Instituto N acional de Salud Pública, Cuernavaca, Morelos, México.

(2) Unidad de Patología. Facultad de Medicina de la Universidad N acional Autónoma de México-H ospital General de México. México, DF, México.

(3) Escuela Militar de Graduados de Sanidad. Secretaria de la D efensa N acional. México, D F, México.

Received on: A pril 8, 2003 - Accepted on: July 21, 2003

Address requests reprints to: $\mathrm{Dr}$. Eduardo Lazcano-Ponce, Director de Investigación en Enfermedades C rónicas del Instituto N acional de Salud Pública. Avenida Universidad N 0. 655, Colonia Santa María A huacatitlán 62508 Cuernavaca, Morelos, México. Correo electrónico: elazcano@ correo.insp.mx 
(pap smear); e) the practice of colposcopy must be regulated to prevent the use of it in healthy women at a population level, thus preventing unnecessary diagnosis and treatment which not only are expensive but also causes unnecessary anxiety to women at risk; $f$ the operation of those clinical laboratories using H PV as a detection strategy must likewise be accredited and regulated and g) the CCSP program for assuring health care quality should meet the expectations of its beneficiaries, and increase the knowledge in cervical cancer related matters. Finally, though a variety of clinical tests on prophylactic and therapeutic vaccines against HPV are recently being developed worldwide; it will take at least from 5 to 10 -years time to have them available in the market. For this reason, it will be necessary to intensify the CCSP programs.AIl these reasons lay emphasis on the need to reinforce actions for C CSP programs.This paper is available too at: http://www.insp.mx/salud/ index.html

Keywords: cervical cancer; developing countries; screening; cervical cytology; colposcopy; HPV; vaccine intervenciones comunitarias regionales que evalúen la efectividad de utilizar el VPH como estrategia adicional a la citología cervical (Pap), e) se debe regular la práctica de la colposco pía para evitar su utilización en mujeres sanas a nivel poblacional, y así,evitar sobre-diagnóstico y sobre-tratamiento, que no sólo tienen implicaciones de elevados costos, sino que producen ansiedad innecesaria en las mujeres en riesgo, f) debe acreditarse y regularse la práctica de los laboratorios clínicos que determinen el VPH como estrategia de detección, y g) el programa de DOC para garantizar calidad, también deberá satisfacer las expectativas de las usuarias, así como aumentar el conocimiento sobre cáncer cer vical. Finalmente, a pesar de que diversos ensayos clínicos de vacunas profilácticas y terapéuticas contra el VPH se desarrollan actualmente a nivel mundial al menos durante un periodo de entre 5 y 10 años las vacunas contra este virus no estarán disponibles comercialmente. Por esta razón, será necesario reforzar las acciones de los programas de DO C. Este artículo también está disponible en: http://www.insp.mx/salud/ index.html

Palabras clave: cáncer cer vical; países en desarrollo; detección oportuna de cáncer; citología cervical; colposcopia; VPH; vacunas
$T$ he exfoliative cytology test (PAP) as a medical intervention at a population-level has proven to be a very effective early detection technique for reducing mortality from cervical cancer (CC) in developed countries, when is used regularly. ${ }^{1}$

Unfortunately, the impact of CC detection in developing countries ${ }^{2}$ is low due to the fact that detection coverage is at its lowest and the quality of the service provided is poor: among the responsible factors we find high-risk population low coverage, poor quality of the health care process and, in some countries, ${ }^{3}$ the unreliability of PAP diagnoses due to the absence of quality control systems and to the lack of ongoing training for the staff in charge. It must be considered that in order to be able to develop a cancer detection program based on conventional cytology, a high level of training and education is required for each and everyone that is involved in the process, especially the health professional collecting the specimens and the cytology technologists involved in the readings, as well as for the colposcopists that round out the diagnose and treatment.

In the face of the situation in developing countries, actions must be implemented to help the cytopathology laboratories improve their efficiency, such as setting up standards to collect specimens correctly, as well as guarantee the reproducibility and the diagnostic validity of the PAP test ${ }^{5}$ throughout ongoing monitoring, total quality control management at the gynecological cytology reading centers ${ }^{6}$ including: a) a well thoughtout quality of the cytopathology laboratory throughout the use of criteria and standards; $b$ ) identifying proble$\mathrm{ms}$, and c) propose corrective actions in resources and accountability, functions, procedures, education and incentives, in order to meet the action's main objective, that of decreasing the number of false negative results.

The quality of the PAP diagnosis is directly related to adequate training on cytopathology, to the consistency of the criteria used in the diagnoses, efficient nomenclature and adequate quality-control mechanisms, for specimen collection as well for diagnosis accuracy. ${ }^{7}$

Furthermore, the CCSP programs in poor countries are highly heterogeneous and rely on the social and economic development of the different geographical areas; in the poorest ones, the common denominator is the short supply in laboratory equipment available to manage high volumes of cytological specimens. It is therefore necessary to modify and to increase the possibilities of use of the conventional cytological test along with new technological alternatives in accordance with existing technical infrastructure and human resources.

Based on the above information, Figure 1 shows the prevention strategies for CC for each prevention level based on the current knowledge of CC's natural history, according to which, based on extensive epidemiological ${ }^{8}$ and laboratory ${ }^{9}$ research, a causal relationship has been shown between the human papilloma virus (HPV) and $\mathrm{CC}^{10}$ and on the basis of these findings, prevention measures are currently under investigation. In that respect, HPV infection is one of the most common sexually-transmitted infections, and it is estimated that at least $50 \%$ of 
sexually active adults have suffered from a HPV genital infection. ${ }^{11}$ A majority of such infections, however, can be effectively controlled by the host's immune response. ${ }^{12}$ Finally, the HPV detection tests plays a major role in the research on the natural history of the infection and on the potential development of prophylactic vaccines, a primary prevention measure likely to decrease to a great extent the incidence of $\mathrm{CC}$ as well as the mortality from the disease. In this order of ideas, listed below are the factors to be considered for the improvement of CCSP programs in poor countries.

\section{Promoting equity in health care}

The definition of inequity may be a notorious difference in the quality and/or quantity of a health care service between two or more communities, with a differential medical coverage depending on ethnic origin, gender, schooling, site of residence or other criteria. ${ }^{13}$
A primary goal of a National Health System is eliminating disparities, and this is why a CCSP program must be promoted and implemented with the same quality in both urban and rural areas, mainly in rural geographical areas and underprivileged urban communities. In order to assess the conditions of equality in $\mathrm{CC}$ detection, indicators must be set up to evaluate the CCSP program coverage and the mortality figures, stratifying by urban and rural regional areas, for the North, Center and South regions of each country.

\section{Promoting actions that ensure extensive coverage}

One of the great benefits of CC screening is involving women at risk, especially those at very high risk, in a CCSP program. In that respect, an extended coverage and adhesion to it are paramount for the effectiveness of a CCSP program. CC cannot be eradicated without

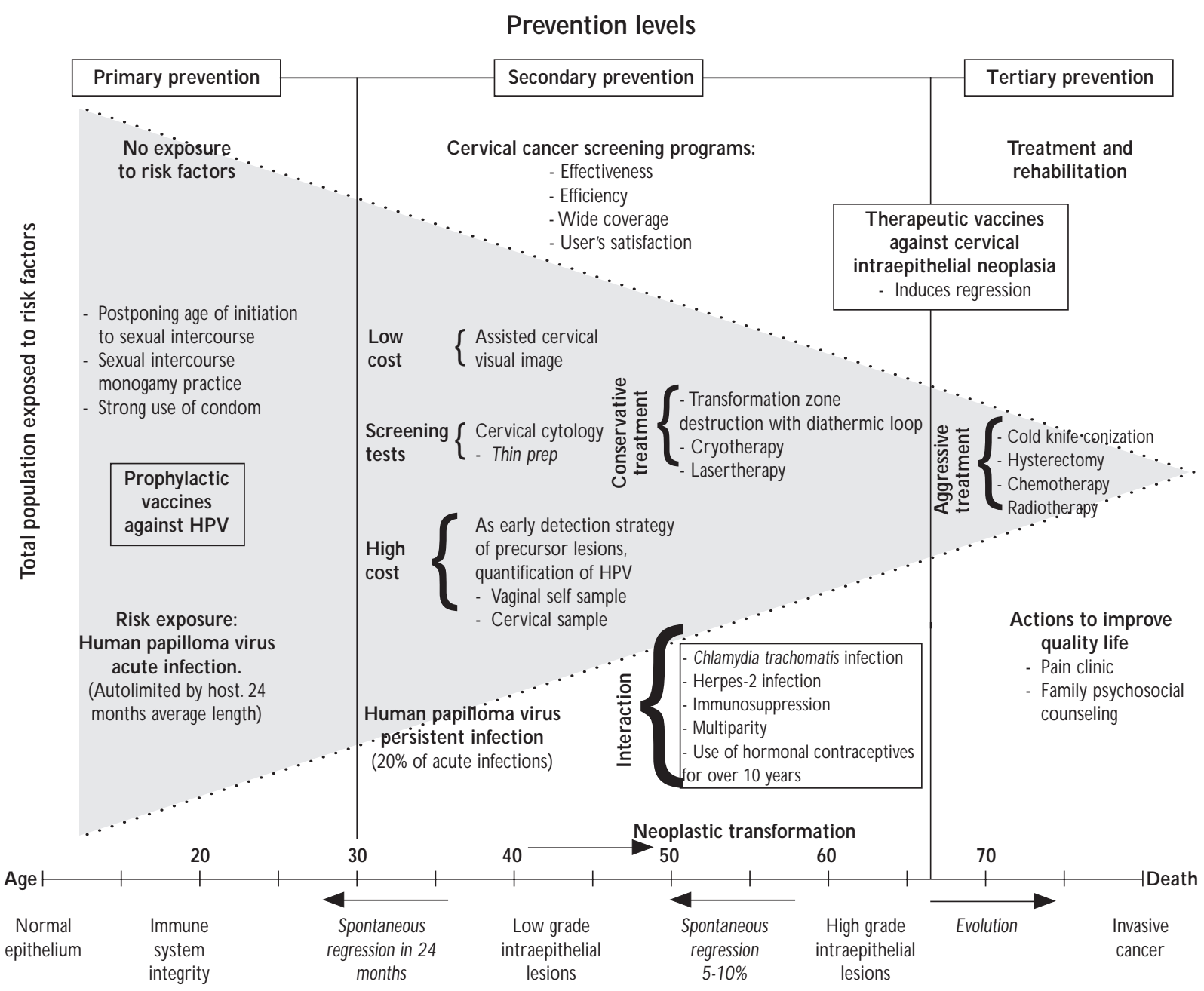

Figure 1. Natural history of Cervical CANCER AND PREVEntion leVels 
an early detection of the precursor lesions by means of a quality PAP test.

\section{Using screening strategies in accordance with health care services availability}

The screening test settings scenarios in developing countries

In countries with a great regional heterogeneity, a variety of screening settings must be regulated and standardized to include a combination of assisted visual inspection, PAP test and HPV detection.

CC detection by means of acetic acid visual inspection. Prior to the advent of PAP in 1944, visual inspection of the cervix was the only strategy available for CC detection. The magnification of the cervix by means of the colposcope, a device invented in 1925 by Hans Hinselmann, revealed tiny invasive cancer cells, invisible to the naked eye. ${ }^{14}$ Back in those times, the carcinoma in situ in the cervix was known, although nobody paid attention to it because its precursor-of-cancer nature was unknown. The image of an exophytic tumor, a necrotic area, or a deep ulceration prompted to carry out a biopsy in order to obtain an accurate diagnosis. Unassisted or colposcopic visual inspection permitted a high number of early diagnoses and the patients treated with the available means (radical surgery or radiotherapy) survived to the disease with an acceptable quality of life. The use of acetic acid, a fortuitous finding by Hinselmann, improved the detection outcomes by permitting a clearer image of the cervical surface. Acetic acid dissolves mucus and other detritus, causes a degree of vasoconstriction with the effect of bringing out the images and showing lesions invisible to the naked eye and qualified as acetowhite for that matter, because they are rich in keratin which precipitates under the action of the acid, with the effect of turning them white and more readily identifiable. Unfortunately, the method's good results were conditioned to the identification of early cases, which today would be classified as Stage IB1 invasive cancer (tumor of less than $4 \mathrm{~cm}$ in its larger dimension), because the treatment outcomes depended on how advanced the lesion was. The late diagnosis of CC, which visual inspection or colposcopy did not contribute to, offered no benefit in terms of the use of health facilities, costs, and caused suffering for the women and their families. A majority of developed countries currently base their CC detection strategy on the PAP, which has proven useful to that effect. ${ }^{15}$ This however is not always feasible in developing countries or certain underprivileged geographic areas whereas there is neither facilities infrastructure nor human resources at least to carry out a PAP test, a low cost alternative being the visual inspection of the cervix with acetic acid.

This strategy must be implemented as follows: women without an abnormal bleeding history are placed in gynecological position and a vaginal speculum is introduced (Figure 2) to permit visual inspection of the cervix. The surface is carefully scrutinized under appropriate lighting. If a macroscopic lesion (exophytic tumor, a necrotic area or a deep ulceration) is found, the patient must be referred to the Colposcopy Clinic, for a complementation of the diagnosis. In the absence of a lesion, the cervix is embrocated with a swab drenched in a $5 \%$ concentration of acetic acid. Two to three minutes later, the swab is removed and the cervix examined. In the presence of macroscopic lesions, as already mentioned, the patient will be referred to the Colposcopy Clinic, likewise in the presence of acetowhite lesions (invisible to the naked eye and visible under the action of acetic acid). Unfortunately, acetowhite lesions are not restricted to potential cervical neoplasia, but are also common in the presence of a metaplasia, some inflammatory process, repair tissue, and atrophy. This constitutes a serious limitation for the method, because it is likely to unnecessarily saturate the colposcopy facilities with false positive outcomes which give the test very little specificity and a low predictive value. In a geographical area where the detection strategy is based on visual inspection with acetic acid, the number and

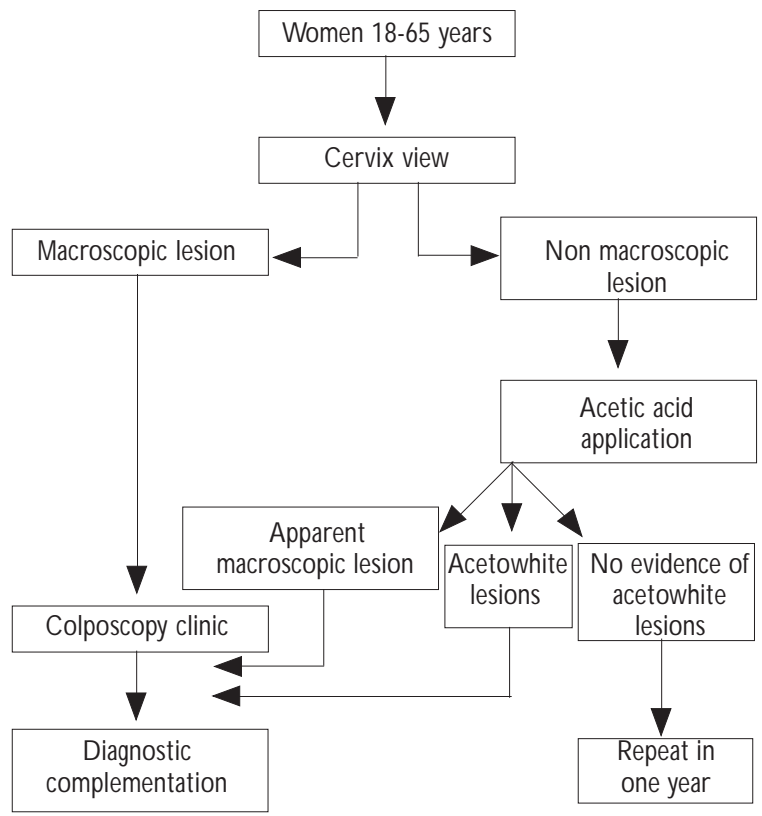

Figure 2. Use of Cervical Visual Image With acetic ACID AS A CERVICAL CANCER EARLY DETECTION STRATEGY 
distribution of colposcopy facilities must be in keeping with this need, rather than with those generated by a cervical cytology detection program.

In the absence of macroscopic and acetowhite lesions, the patient may be reasonably assumed free of invasive neoplasia and precursor lesions, and a repeated exploration after 12 months is recommended.

As for women with a history of abnormal bleeding, it is preferable to carry out a gentle vaginal recognition and in the event of finding an exophitic cervical tumor, without even using the vaginal speculum; the patient should be referred to a Gynecological Oncology clinic. In that respect, the patient's assessment is obviously incomplete, but the idea is to avoid forcing the health care first level units to eventually face the problem of a severe vaginal hemorrhage, the truth being that they might not have the material resources to do it.

The visual inspection of the cervix with or without the application of acetic acid is so easy a proceeding that, in many countries, it is carried out by nurses specially trained to that effect. ${ }^{16,17}$ The outcomes of epidemiological studies with the acetic acid test are diverse. Case-sensitivity varies between $49.4 \%$ and $90 \%$; so does specificity at a $48.5 \%$ to $92 \%$ ratio; positive predictive value (PPV) is between $17 \%$ and $18.9 \%$; and negative predictive value (NPV) fluctuates between $79.8 \%$ and $97 \%$. In those studies comparing the cervical visual inspection and other methods, the PAP, the cervicography or de HPV-DNA demonstration yielded superior outcomes; the cervical visual inspection test, however, may be quite useful in geographical areas lacking health infrastructure. Finally, with the specificity and HPV figures, it can be maintained that the women with negative acetic acid readings are not likely to show, for the time being, an invasive cancer or high grade precursor lesions. The test may be performed yearly to maintain its reliability.

CCSP programs based on cervical cytology. The PAP was described in 1944 as a CC diagnosis method. It soon proved to be able to identify not only the invasive cancer, but also precursor lesions, the treatment of which was and still is simpler, cheaper, and more effective. In those countries where the cytological study has been implemented as a detection strategy in communities, the CC frequency decreased considerably and has remained stable for the past 50 years. ${ }^{18,19}$

A very significant change introduced to improve the PAP's diagnostic reliability has been the appropriate collection of specimens. The smears performed with material accumulated at the bottom of the vaginal pouch, as recommended by Papanicolaou, proved to be inadequate for the diagnosis because the cells had exfoliated some time before and had been exposed to the action of environmental aggressive agents such as the vagina's physiological acidity and the normal resident flora. On the contrary, if the smears include "live" cells, collected directly from the precursor lesion site, the outcomes improve notoriously. Thus, the cytology for the detection of precursor lesions of cervical-uterine cancer stopped being vaginal or cervical-uterine in nature to become specifically cervical.

The programs implemented in developed countries state that the person in charge of collecting specimens must make sure that the whole transformation zone has been duly sampled. Therefore, the cervix must be visualized at the moment of performing the smear. The laboratory staff can never be sure that the whole circumference of the cervix has been sampled, whatever the nature or the content of the cells in the smear. For the pathologist, a smear collected on one half of the cervix will look just the same as one collected on its whole circumference. ${ }^{20}$ Ideally, a PAP smear should include a combined sample (one specimen of endocervical and exocervical cells). This is the reason why the sample collectors must be duly trained in smear performance, and continued medical updating and training is recommended, that is, an improvement process to permit the obtainment of advanced knowledge as well as the development of specific skills and abilities. Provisions should likewise be made for training inexperienced health staff involved for the first time in smear collection. For the specimen collector to be able to evaluate the quality of a cervical smear, and basically, to ensure such quality, the laboratory must mention in the results report the existence or inexistence of indicators of the potential sampling of the transformation zone based on the presence of metaplastic squamous endocervical cells.

The lack of reliable indicators for the transformation zone sampling in atrophic smears, explains why no additional comments are needed in reports on that kind of smears. Likewise, the sampling of the transformation zone may be difficult in the case of women who have received treatment for pre-malignant lesions. In such circumstances, the use of an endocervical brush may be needed in addition to a spatula, and if it is not possible to obtain material from the area, the patient may be referred for a colposcopic evaluation. Primary screening should not be performed only with an endocervical brush. Such smears may contain only endocervical cells and possible do not sample mature squamous cells or epithelium from the transformation zone.

If the sample collector wishes to replicate a smear not showing cytological evidence for the sampling of 
the transformation zone, he must notify it immediately explaining the reasons for his request. Such a proceeding should be considered as a part of the screening process. ${ }^{21}$

The proceeding for PAP specimen collection is the following: in cases without a history of abnormal bleeding, the patient is placed in gynecological position and the vaginal speculum is introduced (Figure 3), permitting the visual inspection of the cervix; under adequate lighting conditions, cervix surface is carefully inspected. If a macroscopic lesion (exophytic tumor, a necrotic area or a deep ulceration) is found, the patient must be referred to the Colposcopy Clinic, for a complementation of the diagnosis. In the absence of a lesion, the PAP is collected, beginning with the ectocervical sample with an Ayre spatula or any modified version of it; the ectocervical surface is gently scraped in a $360^{\circ}$ circular motion. A wooden spatula is needed, making sure to avoid the use of a plastic one, for this material decreases the cells' ability to adhere to the slide. The scrapings are quickly deposited in a linear extended fashion on the distal half of a slide previously marked on one end for correct identification. To avoid the drying out of the ectocervical material, the endocervical sample is taken immediately after with a brush gently introduced in the endocervical canal and rotated in a $180^{\circ}$ motion in a likewise gentle fashion. The material is immediately fixated with the indicated aerosol. The fixator's recipient must be at a $30 \mathrm{~cm}$ distance from the plate, in order for the fluid to fall as fine rain on the slide.

It is paramount to stick to the order specified for the collection of samples; the endocervical sampling may cause light bleeding even with gentle motions due to the very characteristics of the glandular epithelium, there being a vessels network situated immediately below the epithelial layer. Bleeding is more likely in the presence of a certain amount of inflammation, which happens frequently. If the endocervical sample is collected first, the blood contaminates the exocervical surface and goes together with the material on that site, causing a distortion of the cells collected upon performing the smear and making the interpretation more difficult. It is recommended in some texts to perform the PAP with a sole tool used to collect both endocervical and ectocervical material at one time. We do not recommend doing so. Ample evidence exists for the convenience of collecting two different samples, in particular, for collecting the endocervical sample with a brush. 22,23

If the cervix is coated with a normal cervicovaginal secretion, it must be cleaned with a swab soaked in physiological solution previous to the visual inspection and PAP collection. If the secretion's aspect suggests the pre- sence of a vaginal or cervical infection, the patient should be referred to a first level care unit, where the infectious process shall be diagnosed and treated. Only after the treatment and the elimination of the remains of whatever topic medication, can the PAP be performed.

In women with a history of abnormal bleeding, it is recommended to first perform a vaginal palpation without using lubricant, or only wearing a glove moistened with saline solution. If the palpation reveals a cervical exophitic tumor, the patient shall be referred to an Oncological Gynecology clinic, without even introducing the vaginal speculum. If nothing of the sort is found, proceed as mentioned.

It has been said that cytology yields a high ratio of false negative outcomes, which puts a limitation on its usefulness. False negative outcomes should not be found in more than $10 \%$ of studies and a way of achieving this is carrying out carefully every step described. A false negative outcome has no impact on a woman's health if the study is replicated in reasonable amount of time, hence the necessity of her having her first two negative cervical cytology outcomes obtained at a one year interval, in order to later increase the screening periodicity. Furthermore, false negative outcomes are more frequent in low

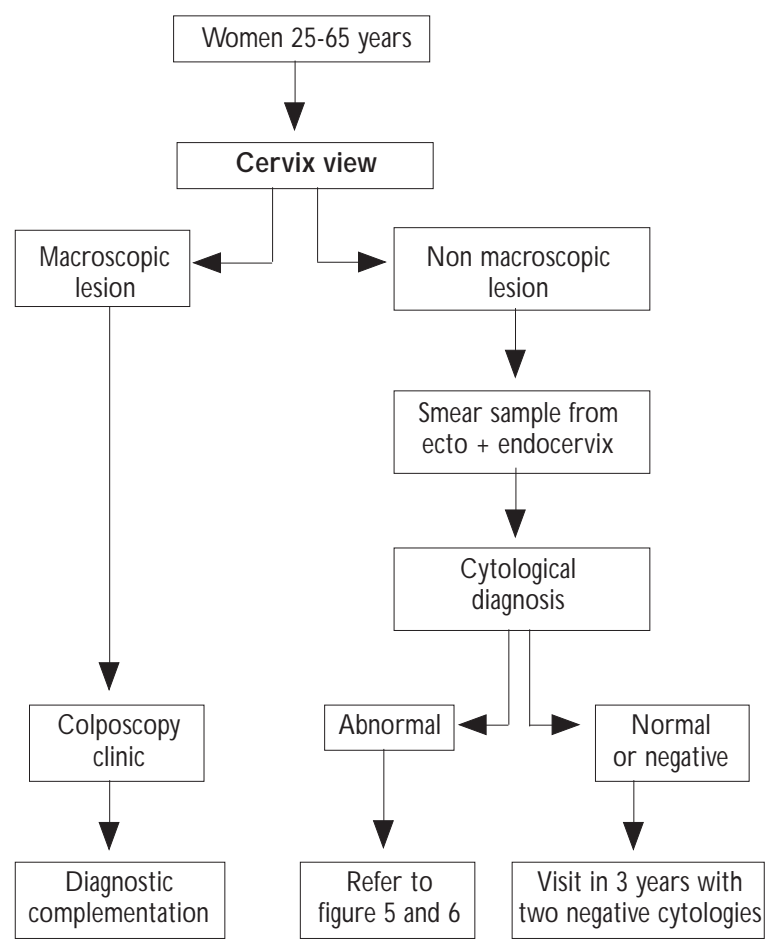

Figure 3. Cervical cytology (smear) as a cervical CANCER DETECTION STRATEGY 
grade intraepithelial lesions (LSIL), whose natural history shows a very high tendency (in 80\% of cases) to disappear. ${ }^{24}$

The age for starting a cytological study for precursor lesions detection is important, due to the needed balance between infrastructure and demand. The first cytological study should be carried out at age 35, or when a woman is considered at risk for having more than two sexual partners. Otherwise, the facilities would be saturated with too many inconsequent LSIL's. The natural progression of CC carcinogenesis is slow enough, so that a PAP test carried out every three years allows sufficient time for an early detection.

Technological variations have been recently introduced in the classical PAP technique, such as thin prep cytology or automated readings. The high costs of both do not warrant their application in a community program, no matter what their usefulness which as yet is not sufficiently documented at that level..$^{25}$

HPV-DNA as a strategy for the detection of CC precursor lesions. Since it became possible to identify the HPVDNA in secretions collected from the internal part of the vagina or the cervix, this test has been used as a strategy for the detection of CC precursor lesions (high grade intraepithelial squamous lesion (HSIL) in population programs. The test, as most detection devices, has both advantages and limitations.

The determination of HPV as a screening strategy is likely to be used at a large scale through the hybrid capture technique (Hybrid capture II) because it can be implemented in a semi-automated fashion. The hybrid capture technique allows identifying over $95 \%$ of the HPV types linked to CC, including types $16,18,31$, $33,35,39,45,51,52,56,58,59$, and $68 .{ }^{26}$

The age-group most appropriate for using the HPV as a CCSP strategy comprises women over 35 years-old, for whom the prevalence of false positive outcomes is very low. The HPV may play other roles, the most obvious of which is improving the treatment of women with low grade or "borderline" lesions. In that context, using the HPV may help identify those women in need of an immediate referral to colposcopy. The HPV must also be used in the post-treatment follow-up in order to be able to monitor complete excisions. The preliminary outcomes of HPV studies as a screening strategy are quite promising because they increase considerably the likehood of identifying high grade lesions undiagnosed by conventional cytology. Especially en poor countries, such a strategy has, however, many limitations, such as:

- In order to be able to evidence the presence of a HSIL, a CC detection test must be administered to a very large population of healthy or apparently healthy women. In that respect, if the PAP has not reached the intended coverage in the national program, the DNA-HPV will hardly have an extensive coverage.

- A CC detection test must sort out between women with HSIL, the healthy ones, and those suffering another type of HPV-caused disease. In this respect, a positive DNA-HPV test identifies those women suffering a HPV genital infection of the latent type (healthy carriers with negative cytology and colposcopy), those with acute (productive), or chronic (transformative), and those with HSIL and invasive cancer. The positiveness, which does not define the type of disease suffered, will cause the referral of the women to a Colposcopy Clinic where their cases shall be valuated, and the group they belong to will be determined. While awaiting these results, a majority of women will experience unnecessary anxiety thinking they might have cancer, when they really are healthy carriers or only show a transitory LSIL likely to disappear within a few months without leaving any consequences. The only relevant women for a detection program are those with HSIL and an invasive cancer. Taking into account the fact that $15 \%$ to $30 \%$ of the women are healthy carriers, ${ }^{27}$ these clinics' population will surely increase, entailing their saturation, which will decrease the quality of the services, provided and increase the detection program's costs.

- The DNA and HPV tests yield a percentage of false negative results and may leave undetected cases of HSIL or cancer. However, as compared with other detection methods, the false negative ratio is much lower, which definitely is an advantage. Other methods such as cytology may decrease the false negative ratio if every step in the program is carried out satisfactorily; and the irreducible false negative ratio (approximately 10\%) can be decreased by a replication of the test, which is effective and does not contribute to a major increase in the program's cost, for individual studies are quite cheap.

- In poor countries, an excessive marketing activity is carried out to convince the clinics of the usefulness of HPV-DNA determination; however, there does not seem to be an accurate clinical awareness of the usefulness of the test in such countries, resulting in inaccurate diagnoses and over-treatment (usually a resection of the transformation zone with a diathermic loop); an ethically objectionable and potentially hazardous proceeding). 
- Among other potential limitations, it must be mentioned that: Amendments to approved CCSP programs would be very costly and require an extensive training program; presently, the unitary cost of HPV is higher than PAP's; the HPV screening is likely to create a financial dependency; and finally, there is no evidence that the HPV screening would decrease the high frequency and mortality rates from CC.

On the other hand, the test does offer certain advantages, among which we find:

The HPV is a potential candidate for screening as a cancer prevention measure. ${ }^{28}$ However, this is still at an early stage and HPV could only be beneficial if it were to prevent $\mathrm{CC}$ through the early detection of asymptomatic precursor lesions. Many of these potential tests use probes systems amplifying many genotypes and based on a cocktail of specific tests. There are presently three probes systems (the MY09/11 and the GP5+/6+), and type II hybrid capture. ${ }^{29}$

All three methods are highly sensitive and specific for the detection of oncogenic viruses and have a potential for automation. Current technological developments should improve specificity without substantially decreasing sensitivity. This possibility should be relevant in terms of public health for it has been shown that HPV-DNA detection in the absence of cytological abnormalities may reveal the presence of high grade cervical intraepithelial neoplasia, which cannot be diagnosed through cytology. ${ }^{22}$ At any rate, every study suggests that adding HPV test to PAP test in CC screening may increase the identification of CC precursor lesions by up to $50-100 \%$. Further studies and prediction schemes will be needed to evaluate the usefulness as well as the cost-effectiveness of the HPV test as a screening strategy in developing countries, and how it could also be used in combination with other diagnosis methodologies.

Another potential advantage is that the sample needed for the detection may be self-collected. In that respect, one of the limitations of the CCSP national program is that the patients refrain from coming to the PAP detection facilities for personal or family reasons having to do with the very process of sample collection. The possibility of self-collection and its proven effectiveness may help going round this difficulty.

Figure 4 shows the algorithm suggested for the implementation of this proposal, considering that regional community interventions must be initiated to valuate the convenience of using HPV additionally to PAP. The HPV-DNA is useful for the valuation of uncertain cytological diagnoses, such as ASC-US. In that respect, the ASC-US cytological diagnosis, as listed in the Bethesda System 1988, was an uncertain diagnosis in need of an urgent revaluation, since it could as well correspond to a healthy woman, or to the carrier of such a serious lesion as an invasive cancer. Under such conditions, the HPV-DNA determination pointed out the group of women at risk, who were immediately referred to colposcopy. The ASC-US diagnosis is no longer found in the revised System Bethesda 2001, and two diagnosis alternatives are suggested instead, that is, ASC-US and ASC-H. The latter obviously must be immediately referred to colposcopy, because the probabilities of it corresponding to a HSIL are high. The former, on the contrary, is rarely associated to a HSIL, and monitoring through repeated cytologies is sufficient. $^{30,31}$

The usefulness of HPV-DNA for post-treatment control

In that respect, if after treatment for HSIL or a more advanced problem, a patient is HPV-DNA negative, the check-up appointments may be at larger intervals. ${ }^{32}$ If a four-monthly evaluation is recommended during the first two years of monitoring, this evaluation may later be appointed annually on the basis of negative HPVDNA outcomes.

\section{The relevance of HPV-DNA for revaluation}

In addition to the harshly criticized ALTS study, many research studies have been conducted to establish the relevance of HPV-DNA in the clinical management of patients. These outcomes are necessary to be able to determine that relevance.

\section{Management of abnormal cervical cytology outcomes}

Since Papanicolaou's time to this date, the way the results of a cervicovaginal cytology study are reported has changed notoriously. From a terminology based on the combination of minus and plus signs and Roman numerals from I to $\mathrm{V}$, one is now used to describe, interpret and diagnose in terms identical to those used in pathology. Such a development has permitted a more select management of each case, for the specified purpose of preventing the overload of colposcopy facilities, which is the next step in the evaluation of most cytological abnormalities. It must be pointed out that the imprecision in Papanicolaou's nomenclature was not relevant in those times, for it was feasible that every woman having from Negative III (an "all-inclusive" category where just about anything would fit) to Positive $\mathrm{V}$ (invasive cancer) outcomes would go to her gyneco- 
logist who, with or without a colposcope, would perform a biopsy in order to be able to make a precise diagnosis. Biopsy could vary from a small fragment obtained with a nipper, to a knife cone, in the operating room. A treatment was determined on the basis of the pathological diagnosis, resulting in an actual decrease in mortality from CC. This would not be feasible now because detection reaches a greater number of women every day and the check-up facilities are overloaded with work.

Cytological nomenclature advanced gradually: the nomenclature proposed by Richart ${ }^{33}$ including term: 1, 2, and 3 grade Cervical Intraepithelial Neoplasia (CIN) replaced such terms as mild, moderate, and severe dysplasia, and carcinoma in situ used in the WHO's recommendations and, finally, there was the Bethesda System, created in $1988^{34}$ and revised in 2001..$^{35}$ Despite the differences in appellations and the various ways of classifying the precursor lesions, the terms are entirely equivalent. The recommendations made in this article include those derived from the Bethesda System 2001 classification.

In this context, it is estimated that very high-quality detection programs ${ }^{31}$ of cytological studies result abnormal in a $7 \%$, as where is unorganized programs it goes from $10 \%$ to $12 \%$. More importantly, many of such abnormalities can and must be managed, at least temporarily, at the detection site or health care alternate facilities other than the Colposcopy Clinics. A community program for $\mathrm{CC}$ detection must take care that the Colposcopy Clinics do not become overloaded, for this would impact negatively on the quality of the service provided, which would be detrimental for both the patients and the program.

The Bethesda System 2001 cytological diagnoses belong to two main categories:

1. Diverse cell abnormalities unrelated to precursor lesions or cancer, and

2. Squamous and glandular cell alterations linked to such diagnoses. The management of each potential cytological diagnosis will be analyzed

Non-neoplastic alterations (Figure 5)

The presence of microorganisms. Evidence of a microorganism in the lower genital tract (Tricomonas vaginalis,

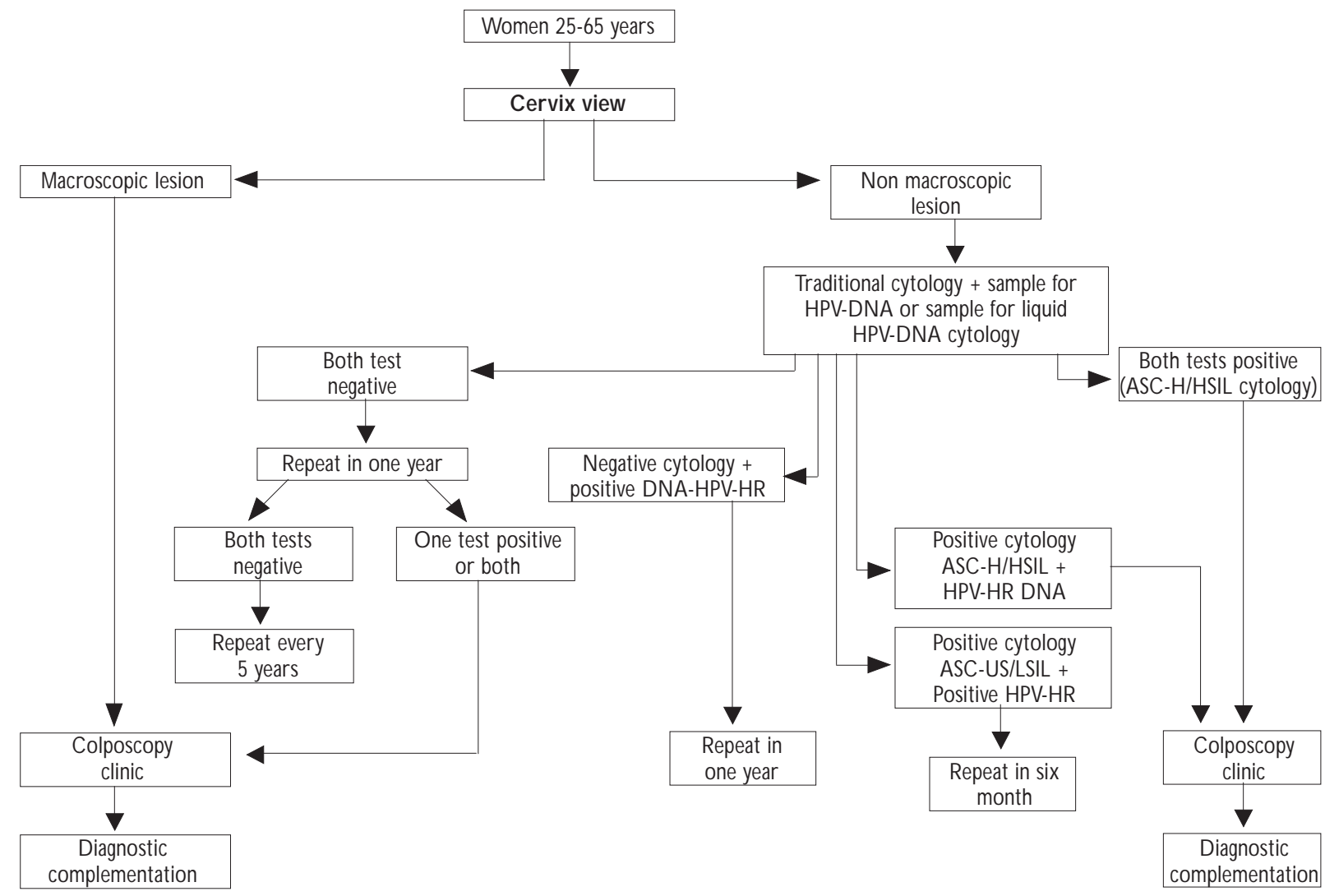

Figure 4. Determination of high risk HPV as a cervical cancer early detection strategy in developing COUNTRIES 


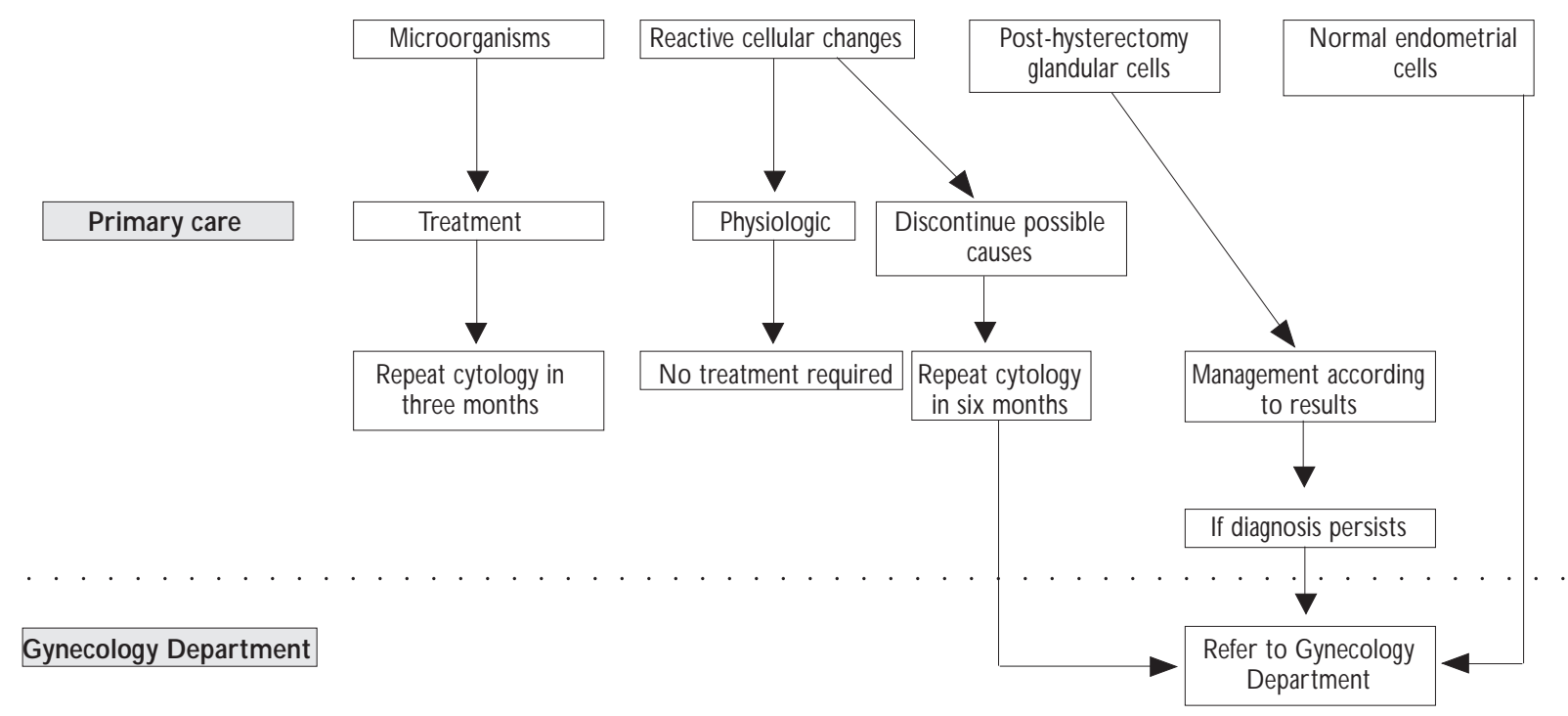

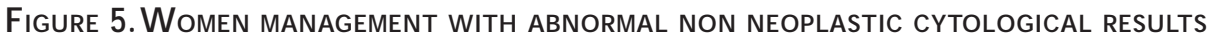

Candida or of some other organisms such as Gardnerella vaginalis, etc.) will call for a specific treatment. Cervical cytology must be performed three months later, and later treatment will depend on the outcome.

Other non-neoplastic findings. Reactive cellular changes. These changes are important because they often complicate the cytological diagnosis. This is why it is important to obtain clinical data concerning radiation history and the use of an intrauterine device. In both instances, the cytological abnormalities are irrelevant.

The inflammation-linked reactive cellular changes include the metaplastic cells which may be immature, nevertheless reflecting a physiological process. They may also evidence an unbalance in the vaginal flora, usually associated to the action of external agents such as vaginal douches, spermicides, lubricant jellies, intercourse with a partner using a condom or the vaginal application of medicines. If the inflammation is mild (graded from + to ++ ) the possibilities of a cytological diagnosis for the detection of precursor cells or CC are not hindered, and there is no need to recommend any changes. However, in the presence of a severe inflammation (graded from +++ or ++++$)$ the patient must be referred to a specialized facility. The PAP shall be replicated six months later, and the outcome shall determine the management of patient.

A cytological atrophy picture corresponds to a physiological state in certain stages of life. The cytological diag- nosis may prove difficult to the laboratory, although it does not have any particular implications for the physician.

The presence of post-hysterectomy glandular cells shows that the cervix resection was incomplete, that part of the squamocolumnar junction remains, that there is metaplasia and therefore, transformation zone. These patients must participate in the CCSP program just as any other woman. An incomplete hysterectomy does not provide any protection.

The presence of normal endometrial cells in postmenopausal women, even in the absence of symptoms, may be the first indication of a glandular precursor lesion of the endometrium or an endometrial adenocarcinoma, and a hysteroscopy or curettage is recommended.

\section{Neoplastic cytological alterations (Figure 6)}

Atypical squamous cells with undetermined significance (ASCUS). This category, proposed on the basis of the Bethesda System 1988 nomenclature, was divided into two sections for the Bethesda System 2001 revised version: a) atypical squamous cells with undetermined significance (ASC-US), favoring a reactive lesion, and b) atypical squamous cells cannot exclude HSIL (ASC-H). It is recommended that category a) be managed as a LSIL and category $b$ ) be managed as HSIL, the frequency of HSIL diagnosed through biopsy is between $5-17 \%$ in the former, and $24-94 \%$ in the latter. ${ }^{36}$

ASC-US/LSIL. LSIL natural history shows its disappearance within 24 months, which actually occurs in $80 \%$ 


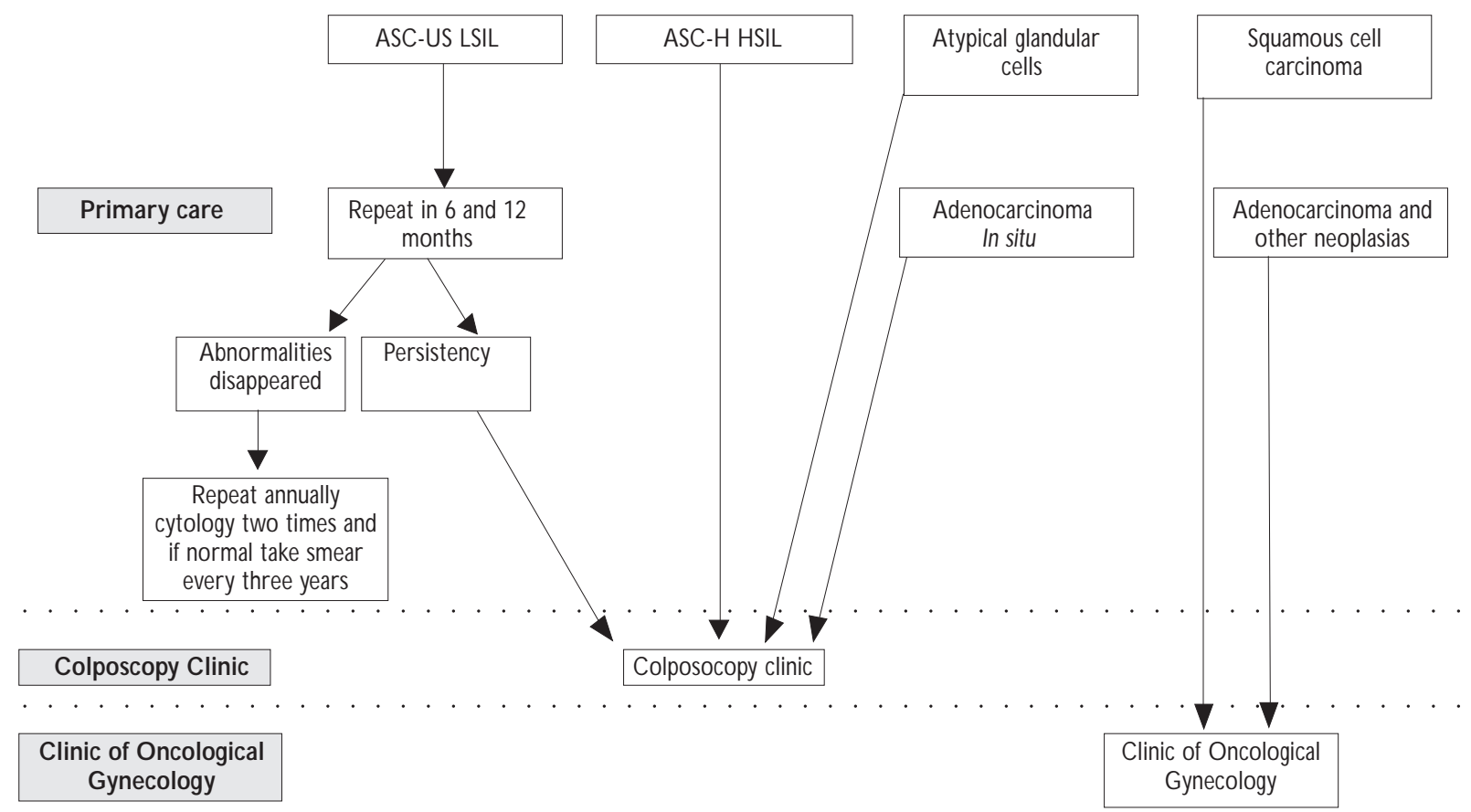

Figure 6.W OMEn MANAGEMENT WITH ABNORMAL NEOPLASTIC OR POSSIBLY NEOPLASTIC CYTOLOGICAL RESULTS

of cases. ${ }^{37}$ Therefore, in the presence of ASC-US and LSIL diagnoses, it is recommended to repeat the cytology study 6 and 12 months later. If both studies evidence a disappearance, repeat the PAP twice and go through the detection process every three years thereafter; if both studies evidence persistence, the patient must be referred to CC, just as well as if a more severe diagnosis were made.

ASC-US under special circumstances. a) Post-menopausal woman: recommend vaginal estrogens for seven days and a PAP test five days after the conclusion of treatment. Some SIL cases not visible due to atrophy thus become apparent. If the cytology turns out negative after the estrogen treatment, perform it again six months after a new epithelial maturation. If preferred, oral estrogens may be prescribed. Two negative results send the patient again to a four-monthly control; $b$ ) woman with immunosuppression: immediately refer the patient to the colposcopy clinic, and c) pregnant woman: must be monitored normally and revaluated after the puerperium.

ASC-H/HSIL. Immediately refer to the colposcopy clinic. If the colposcopy of a patient with ASC-H turns out negative and the woman is post-menopausal, immediately use the epithelial maturation with estrogens; if she is still menstruating, repeat the cervical cytology six months later and manage according to the results obtained.

Squamous cell carcinoma. Refer immediately to the Gynecological Oncology Clinic.

Atypical glandular cells. No matter what the classification of the abnormalities, whether or not favoring neoplasia, whether specific (endocervical or endometrial) or unspecific (glandular), the women with atypical glandular cells must be referred immediately to the Colposcopy Clinic.

In situ endocervical adenocarcinoma. Refer immediately to the Colposcopy Clinic.

Adenocarcinoma and other malignant neoplasias. The women with such results, whether or not the cause can be determined, must immediately be referred to a Gynecological Oncology Clinic.

The correct interpretation of a PAP will contribute to the appropriate management of patients without overloading the colposcopy clinics. Otherwise, the women are liable to experience anxiety and undergo unnecessary biopsies; their ailments may as well be overdiagnosed and overtreated, all of it using health care time which would be more profitably dedicated 
to those showing abnormalities, with the consequent decrease in the care of all.

\section{The need to regulate the practice of colposcopy}

The practice of colposcopy must be regulated in order to prevent its population-level usage on healthy women, to avoid overdiagnosis as well as overtreatment, which does not only entail high costs, but also produces unnecessary anxiety among the women at risk. We all know that the diagnostic and therapeutic processes are not free of immediate complications as well as long-term undesirable effects. Their application to healthy women without ailments which do not require them imply, not only a moral responsibility, but also a violation of scientific, medical, legal, and ethical principles.

For all these reasons, the overloading of the colposcopy clinics must be avoided for it directly impairs the quality of health care. In developing countries, colposcopy must be regulated and evaluated through internal and external quality control mechanisms, in order to maintain a permanent quality control and prevent a prevalent profit-oriented practice.

\section{The need to regulate the operation of the HPV clinical laboratories}

The determination of high-risk HPV-DNA through such techniques as the capture of II or III generation hybrids (HC II) is fairly simple. The test has distinct advantages over in tube hybrid capture ${ }^{38}$ as well as in situ hybridization..$^{39} \mathrm{HC}$ II implies the reading of light signals proportionate to the amount of HPV-DNA, which is an extra advantage: the greater the viral load, ${ }^{40}$ greater the risk of finding a precursor lesion or CC.

Quantifying the amount of HPV-DNA is easy with the proper equipment. Since the test does not use viral genome replication, but rather, bases the determination on the amount contained in the sample, positiveness will rely on passing the negativeness threshold which is $1 \mathrm{pg} / \mathrm{ml}$ for HC II, and $10 \mathrm{pg} / \mathrm{ml}$ for HC I.

The (internal and external) quality control mechanisms in laboratories performing these tests must be in strict abidance of the recommendations regulating laboratory operation in developing countries, under close government supervision as well as of those medical associations interested in reliable results. ${ }^{41}$

\section{Ensuring CCSP programs user's satisfaction}

Term "quality" is of a complex and multidimensional nature. It encompasses notions of effectiveness, efficien- cy, scientific and technical quality, management, perception, expectations, communication, adequateness, coordination, accessibility, availability, distribution, satisfaction, privacy, credibility, professional competen$c y$, credit, structural support, and safety. ${ }^{42}$ Setting up research lines for quality should allow us to pursue an improvement of CCSP programs. In order to attain that goal, there is a need for: a) methods for problem-approaching; b) methods for setting goals to be pursued by health care facilities, managers and decision makers; c) methods taking into account the variability in professional practice, through improvements in internal communication; d) methods chosen to ensure the satisfaction of users, clients, patients, individuals, citizens, and, finally, inter alia, and e) methods centered on the promotion of improvement opportunities.

The advancement of health technologies in CCSP programs shall allow an improvement of the facilities' ability to identify and bring a solution to problems.

It will also rely on the training and/or adaptation of highly competent staff that shall be in charge of developing and implementing the strategic detection methodologies needed to meet the population's needs and demands.

\section{Clinical tests to determine the effectiveness of prophylactic vaccines against $H P V$}

Although the administration of a vaccine against HPV has proven to be $100 \%$ effective in the reduction of HPV-16 infections as well as of those related to cervical intraepithelial neoplasia, ${ }^{43}$ and that a variety of clinical tests for polyvalent prophylactic and therapeutic vaccines against HPV are presently conducted worldwide, the HPV vaccines will not be commercially available for a 5 to 10 -year time period. For this reason, it will be necessary to intensify the early detection of cervical cancer.

\section{Conclusions}

An CCSP program must be restructured to a) mainly address rural geographic regions and underprivileged urban areas; b) foster actions aimed at ensuring a wide coverage and similar quality of services in all these regions; c) use screening strategies in keeping with the availability of health care services. In countries with a great regional heterogeneity, a variety of screening settings must be regulated to include a combination of assisted visual inspection, cervical cytology and HPV determination; d) regional community intervention must be initiated to evaluate the usefulness of using 
HPV as a strategy additionally to cervical cytology; e) the practice of colposcopy must be regulated in order to avoid its use with healthy women at a community level, this, for the purpose of preventing overdiagnosis and overtreatment, which not only entail high costs, but also cause unnecessary anxiety in the women at risk; furthermore, f) the practice of clinical laboratories using HPV as a detection strategy must be accredited, and g) in order to ensure quality services, the CCSP program must also meet the users' expectations and improve their knowledge of cervical cancer. Finally, though a variety of clinical tests on prophylactic and therapeutic vaccines against HPV are presently being developed worldwide; they shall not be commercially available for a 5 to 10 -year time period. For this reason, it will be necessary to intensify the CCSP programs.

\section{References}

1. Lara E, D ay EN , Hakama M. Trends in mortality from cervical cancer in the N ordic countries:Association with organized screening programes. Lancet 1987:1247-1249.

2. Lazcano-Ponce E, Rascón-Pacheco R, Lozano R,Velasco E. Mortality from carcinoma of the uterine cervix in Mexico: impact of screening 1980-1990. Acta Cytol 1996;40:506-512.

3. Miller AB. Cervical cancer screening programes, Geneva:W orld Health $O$ rganization, 1992.

4. Mitchell H. Consistency of reporting endocervical cell.An intralaboratory and interlaboratory assessment. Acta Cytol 1994:38:310-314

5. Koss LG. Cytology: Accuracy or diagnosis. Cancer 1989;64:249-257. 6. Alonso P, Lazcano E. Q uality control in cytopathology laboratories in six Latin A merican Countries. In:W ied G, Keebler C, Rosenthal D, Schenck $U$, Somrak T,Vooijs $P$ eds. Compendium on quality assurance, proficiency testing and workload limitations in clinical cytology C hicago: Tutorials of Cytology,1995:115-121.

7. Lundenberg G. Q uality assurance in cervical cytology. The papanicolaou smear. JAMA 1989;262:1672-1679.

8. Muñoz N , Bosch FX, De Sanjose S, Tafur L, Izarzaguza I, Gili M et al. The causal link between human papillomavirus and invasive cervical cancer:A population-based case-control study in Colombia and Spain. Int J Cancer 1992;52:743-749.

9. Zur Hausen H. Papillomaviruses in human cancer. Appl Pathol 1987;5(1):19-24.

10.W alboomers JMM, Jacobs MV, Manos M, Bosch FX, Kummer JA, Shah $\mathrm{K}$ et al. Human papillomavirus is a necessary cause of invasive cervical cancer worldwide.J Pathol 1999;189:12-19.

11. Koutsky L. Epidemiology of genital human papillomavirus infection. Am J Medicine 1997;102:3-8.

12. Galloway $D$. Is vaccination against human papillomavirus a possibility? Lancet 1998;352:SIII22-SIII24.

13. Pearcy JN , Keppel KG .A Summary measure of health disparity. Public Health Reports 2002;117:273-280.

14. Hinselmann H.Verbesserung der Inspektionmöglichkeiten von Vulva, Vagina und portio. Münch Med W schr 1925;72:1733.
15. Bjorge T, Thoresen SO, Skare GB. Incidence, survival and mortality in cervical cancer in N orway, 1956-1990. Eur J Cancer 1993;29A (16):2291-2297.

16. Megevand $E$, D enny L, D ehacek $K$ y cols. Acetic acid visualization of the cervix:An alternative to cytologic screening. 0 bstet Gynecol 1996;88:383-386.

17. University of Zimbawe/JH PIEG O Cervical C ancer Project.Visual inspection with acetic acid for cervical-cancer screening: test qualities in a primary-care setting. Lancet 1999;353:869-873.

18. Sigurdsson K. Effect of organized screening on the risk of cervical cancer. Evaluation of screening activity in Iceland,1964-1991. Int J Cancer 1993 Jun 19;54(4):563-70.

19. Herrero R. Epidemiology of cervical cancer.J N atl Cancer Inst Monogr 1996;21:1-6.

20. Editorial. Cell Content of Cervical Smears. Cytopathol 1990;1:129-130.

21. Herbert A. A chievable Standards, Benchmarks for Reporting and

Criteria for Evaluating Cervical Cytopathology. Cytopathol 1995;6:1-32.

22. Martin-Hirsch P, Lilford R, Jarvis G, Kitchener HC. Efficacy of

cervical-smear collection devices: a systematic review and meta-analysis. The Lancet 1999; 354 (9192):1763-1770.

23. McC ord ML, Stovall TG, Meric JL, Summitt RL Jr, Coleman SA

Cervical cytology:A randomized comparison of four sampling methods. Am J 0 bstet Gynecol. 1992;166:1772-1779.

24. Ho GY, Bierman R, Beardsley L, Chang CJ, Burk RD. N atural history of cervicovaginal papillomavirus infection in young women. $N$ Engl J Med 1998;338(7):423-438.

25. Sawaya GF, Grimes DA. N ew technologies in cervical cytology screening: A word of caution. 0 bstet Gynecol 1999:94:307-310. 26. Iftner T,Villa LL. Chapter 12: Human papillomavirus technologies. J $\mathrm{N}$ atl C ancer Inst Monogr. 2003;(31):80-8.

27. Salmerón J, Lazcano-Ponce E, Lörincz A, Hernández M, Hernández P, Leyva A et al. Comparison of HPV-based assays with Papanicolaou smears for cervical cancer screening in Morelos State, Mexico. Cancer Causes and Control 2003;14 (6): 505-512.

28. Lörincz AT, Richart RM. Human papillomavirus D N A testing as an adjunct to cytology in cervical screening programs. Arch Pathol Lab Med 2003;127(8):959-968.

29. C astle PE, Schiffman M, Gravitt PE, Kendall H, Fishman S, D ong H et al. Comparisons of HPV DNA detection by MY09/11 PCR methods. J Med Virol 2002;68(3):417-423.

30. Garner El. Cervical cancer: D isparities in screening, treatment, and survival. Cancer Epidemiol Biomarkers Prev 2003;12(3):242S-247S. 31.W right TC Jr, Cox JT, Massad LS, Twiggs LB,W ilkinson E);ASC C PSponsored Consensus Conference. 2001 Consensus Guidelines for the management of women with cervical cytological abnormalities. JAMA. 2002;287(16):2120-9.

32. Paraskevaidis E, Koliopoulos G, Alamanos Y, Malamou-Mitsi V, Lolis $\mathrm{ED}$, Kitchener HC. Human papillomavirus testing and the outcome of treatment for cervical intraepithelial neoplasia. 0 bstet $\mathrm{G}$ ynecol 2001;98(5 Pt 1):724-725.

33. Richart RM. Current concepts in obstetrics and gynecology. The patient with abnormal Pap smear - screening techniques and management. N Engl J Med 1980;302:332-334.

34. N ational C ancer Institute W orkshop. The 1988 Bethesda System for reporting cervical/vaginal cytologic diagnoses. JAMA 1989;262:931-934. 35. Solomon D, D avey D, Kurman R, Moriarty A, 0 'C onnor D, Prey M, and Forum Group Members; Bethesda 2001 W orkshop. The 2001 Bethesda System: terminology for reporting results of cervical cytology. JAMA. 2002;287(16):2140-2141.

36. 0 'Meara AT. Present standards for cervical cancer screening. Curr 0 pin 0 ncol 2002;14:505-511.

37. Elfgren K, Kalantari M, Moberger B et al. A population-based five year follow-up study of cervical human papillomavirus infection. Am J 0 bstet Gynecol 2000;183:561-567. 
38. Lörincz AT: Molecular methods for the detection of human papillomavirus infection. 0 bstet Gynecol C lin NA 1998;23:707-730. 39. A utillo-Touati A, Joannes M, d'Ercole C, Robaglia-Schlupp A, Lambert A, Mazzella $E$ et al. HPV typing by in situ hybridization on cervical cytologic smears with ASC US. Acta C ytol. 1998 MayJun;42(3):631-8.

40. Sun Sun CA, Liu JF,W u D M, N ieh S,Yu CP, Chu TY.Viral load of highrisk human papillomavirus in cervical squamous intraepithelial lesions. Int J Gynaecol 0 bstet. 2002;76(1):41-47.
41. Steindel SJ, G ranade S, Lee J,Avery G, Clarke LM, Jenny RW et al. Practice patterns of testing waived under the clinical laboratory improvement amendments.Arch Pathol Lab Med. 2002;126(12):1471-1479. 42. Saturno PJ, Q uintana $O$, Varo J. ¿Q ué es la calidad?. En: Saturno PJ, et al.Tratado de calidad asistencial en atención primaria.Tomo I. Murcia: Du Pont Pharma, 1997:19-45.

43. Koutsky LA,Ault KA,W heeler CM, Brown DR, Barr E,Alvarez FB et al. Proof of Principle Study Investigators. A controlled trial of a human papillomavirus type 16 vaccine. N Engl J Med, 2002;347(21):1645-1651. 